\title{
Mechanical properties and biocompatibility of polymer infiltrated sodium aluminum silicate restorative composites
}

\author{
Huining WANG ${ }^{a}$, Bencang $\mathrm{CUI}^{b}$, Jing $\mathrm{LI}^{b}$, Shu $\mathrm{LI}^{a,}{ }^{,}$, \\ Yuanhua $\mathrm{LIN}^{b}$, Deping $\mathrm{LIU}^{c}$, Ming $\mathrm{LI}^{b}$ \\ ${ }^{a}$ Department of Periodontology, School and Hospital of Stomatology, Shandong Provincial Key Laboratory of Oral \\ Tissue Regeneration, Shandong University, Jinan 250012, China \\ ${ }^{b}$ State Key Laboratory of New Ceramics and Fine Processing, School of Materials Science and Engineering, \\ Tsinghua University, Beijing 100084, China \\ ${ }^{c}$ Department of Cardiology, Beijing Hospital, National Center of Gerontology, Beijing 100730, China
}

Received: September 22, 2016; Revised: November 14, 2016; Accepted: November 18, 2016

(C) The Author(s) 2016. This article is published with open access at Springerlink.com

\begin{abstract}
A new type of polymer-infiltrated-ceramic-network composites (PICNs) was fabricated by infiltrating methacrylate-based monomers into partially sintered porous ceramics. The mechanical properties (flexural strength, flexural modulus, elastic modulus, Vickers hardness, fracture toughness) were investigated and compared with that of the natural tooth and common commercial CAD/CAM blocks. Our results indicated that sintering temperature and corresponding density of porous ceramics have an obvious influence on the mechanical properties, and PICNs could highly mimic the natural tooth in mechanical properties. The biocompatibility experiments evaluated through in vitro cell attachment and proliferation of BMSCs showed good biocompatibility. The mechanical properties and biocompatibility confirmed that PICN could be a promising candidate for CAD/CAM blocks for dental restoration.
\end{abstract}

Keywords: dental composite; polymer-infiltrated-ceramic-network composites (PICNs); CAD/CAM blocks; mechanical properties; biocompatibility

\section{Introduction}

Polymer-infiltrated-ceramic-network composites (PICNs), as new composites, realize higher inorganic component loadings through infiltrating polymerizable monomers into porous ceramics and curing rather than filling inorganic particles into organic mixtures. Bis-GMA (2,2-bis[ $p$-(2'-hydroxy-3'-methacryloxypropoxy)pheny lene]propane), UDMA (1,6-bis(methacryloxy-2ethoxycarbonylamino)-2,4,4-trimethylhexane), and

\footnotetext{
* Corresponding author.

E-mail: lishu@sdu.edu.cn
}

TEGDMA (triethylene glycol dimethacrylate) are mostly used monomers [1,2]. Resultant structure is composed of dual networks, i.e., the porous ceramic block and the spatial continuous organic phase. Interpenetrating phase composites have been utilized since the 1990s and continued their applications in the field of dental restoration [3]. The composites pioneered in the 1990s were fabricated by infiltrating glass phases into porous crystalline ceramic networks. However, these composites were essentially classified as all-ceramic systems. The ultrahigh hardness caused the abrasion of opponent natural tooth, and the high sensitivity to micro-cracks brought early failure of 
restoration. And therefore, PICNs are acquiring their dominant positions in dentistry instead of glass-infiltrated-ceramics.

The idealistic condition is to realize high simulation of natural tooth in terms of both structure and properties. Aesthetic properties, mechanical properties, and biocompatibilities are the main topics of dental restorations [4]. All of glass-infiltrated-ceramics, filled composites, and PICNs can achieve high aesthetic properties. However, PICNs possess more similar mechanical properties to natural tooth than filled composites and glass-infiltrated-ceramics. The specific structure of dual networks, i.e., porous ceramics and continuous organic phases, enables this kind of materials with characteristics of ceramics and polymers. Hardness, strength, and wear resistance are attributed to the ceramic parts, while the polymer parts are responsible for flexibility and machinability. VITA ENAMIC is a kind of representative commercial PICNs, which was introduced by VITA in 2013. Lava Ultimate is essentially filled composite, launched by $3 \mathrm{M} \mathrm{ESPE}$ in 2012. In most terms, Lava Ultimate is comparable to VITA ENAMIC, even with flexural strength higher than that of the latter. However, with a low modulus only half that of the natural dentin and VITA ENAMIC, Lava Ultimate would be subjected to elastic deformation twice that of the natural dentin and VITA ENAMIC. The difference of modulus between restorative materials and the natural dentin causes the unmatched transfer of force, and causes the early failure of restoration ultimately. Recently, 3M ESPE announced in a notice that the crown indication was removed from that product, which had been assured just at the beginning of launch.

Biocompatibility is an important property of dental restorative materials, which describes the ability of biomaterials to interact appropriately with the host $[5,6]$. Biomaterials with low biocompatibility could cause adverse effects, including systemic toxicity, local reactions, allergic reactions, and other reactions [6]. The adverse effects are mainly attributed to the components that are released from the composites [7]. The components are mainly unpolymerized monomers because of oxygen-inhibition. In this term, indirect restorative composites show more excellent biocompatibility than direct ones, because the surface layer could be removed mechanically from cured blocks [8]. Cell culture is a common in vitro evaluation of biocompatibility.

In this paper, the mechanical properties including flexural strength, flexural modulus, elastic modulus, hardness, and fracture toughness were compared with respect to the sintered temperature of the green body. In vitro cell proliferation properties were compared among 550 and $850{ }^{\circ} \mathrm{C}$-sintered and cured pure resin samples.

\section{Experimental procedure}

\section{1 Fabrication of the samples}

Sodium aluminum silicate was purchased from Degussa AG Company (SIPERNAT 820A, Degussa AG, Germany). As sintering temperature and heat-retaining time directly affect the density of ceramics, porous ceramic blocks were fabricated by partially sintering sodium aluminum silicate through controlling the above factors (reducing sintering temperature and shortening heat-retaining time). Firstly, sodium aluminum silicate powder, with PVA aqueous solution (3 $\mathrm{wt} \%)$ as adhesive, was pressed into block green bodies through mold pressing at $3 \mathrm{MPa}$. The green bodies were then densified with isostatic cool pressing. The pressure was $220 \mathrm{MPa}$, and the staying time was $1.5 \mathrm{~min}$. Then the blocks were sintered at different temperatures (550 and $850{ }^{\circ} \mathrm{C}$ ). A porous structure of sodium aluminum silicate was obtained through heating rate of $5{ }^{\circ} \mathrm{C} / \mathrm{min}$ and heat preservation of $1 \mathrm{~min}$ in the case of forming dense ceramics. Polymerizable monomers were infiltrated into the porous block by vacuum capillary action at a vacuum degree of $-0.1 \mathrm{MPa}$ in vacuum drying oven and cured at $70{ }^{\circ} \mathrm{C}$ for $16 \mathrm{~h}$. The polymerizable monomer mixtures contained Bis-GMA and TEGDMA (Aladdin Reagents Company, Shanghai, China), the mass ratio of which was 50:50. As the viscosity of Bis-GMA was rather high, TEGDMA was used as diluent [9]. Dibenzoylperoxide, BPO (J \& K Scientific LTD.), was used as thermo-initiator (2 $\mathrm{wt} \%$ ).

\section{2 Flexural property tests}

Flexural strength and modulus were calculated from results of three-point bending tests using a universal testing machine (AGS-X, SHIMADZU, Japan). The cured blocks were cut into three-point bending bars of $2 \mathrm{~mm} \times 2 \mathrm{~mm} \times 25 \mathrm{~mm}$ using a diamond saw with rotating speed of $3000 \mathrm{rpm}$ and feeding speed of $6 \mathrm{~mm} / \mathrm{min}$. The cut samples were polished until no obvious scratches could be observed. The speed of crosshead was $0.5 \mathrm{~mm} / \mathrm{min}$ when exerting forces. 
The flexural strength was calculated by Eq. (1) according to ISO-4049:

$$
\sigma_{\mathrm{f}}=\frac{3 F L}{2 b h^{2}}
$$

where $F$ is the load at fracture, $L$ is the roller span distance, $b$ is the width, and $h$ is the height of the sawed specimen.

The flexural modulus was calculated from the results of three-point bending tests by Eq. (2):

$$
E_{\mathrm{f}}=\left(\frac{F}{a}\right) \frac{L^{3}}{4 b h^{3}}
$$

where $L$ is the roller span distance, $b$ is the width, $h$ is the height of the specimen, and $(F / a)$ is the slope of the force-displacement curve.

\section{3 Fracture toughness tests}

The fracture toughness $\left(K_{\text {Ic }}\right)$ was measured through standard SENB (single-edge-notched beam) method in a three-point-bending format that flexural properties were tested. The blocks were sawed into $2 \mathrm{~mm} \times 4 \mathrm{~mm} \times$ $20 \mathrm{~mm}$ specimens. A notch was sawed at the middle of each sample. The force was measured at fracture with crosshead speed of $0.05 \mathrm{~mm} / \mathrm{min}$. The supporting span was $15 \mathrm{~mm} . K_{\text {Ic }}$ was calculated from the following equation:

$$
K_{\mathrm{Ic}}=\frac{F L}{B W^{3 / 2}} f\left(\frac{a}{W}\right)
$$

where $F$ is the load at fracture, $L$ is the lower supporting span, $B$ is the breadth of the beam, $W$ is the width of the beam, $a$ is the length of the notch, and $f(a / W)$ is the geometrical factor.

\section{4 Nano-indentation tests}

The results of nano-indentation tests were used to calculate elastic modulus $(E)$ and Vickers hardness. Specimens $(4 \mathrm{~mm} \times 2 \mathrm{~mm} \times 10 \mathrm{~mm})$ were cut from composite blocks and polished. For each specimen, five indentation points were located randomly over the surface with a nano-indenter (XP, Keysight Technologies, USA). The maximum depth of indentation was $1000 \mathrm{~nm}$. The force and length of resultant diagonal were recorded simultaneously during each holding interval, which were used to calculate the Vickers hardness. Stress-strain characteristics in progress were recorded and used to calculate the elastic modulus.

\section{5 Brittleness index calculation}

Brittleness index was used to evaluate the machinability of dental restorative composites, which is calculated according to Eq. (4):

$$
B I=\frac{H_{\mathrm{V}}}{K_{\mathrm{Ic}}}
$$

where $H_{\mathrm{V}}$ is the Vickers hardness, $K_{\mathrm{Ic}}$ is the fracture toughness.

\section{6 Mid-infrared tests}

Uncured resin was used as a control to calculate the degree of double conversion through mid-infrared spectroscopy. Because of the constancy of aliphatic $\mathrm{C}=\mathrm{C}$ absorption and aromatic $\mathrm{C}-\mathrm{C}$ absorption before and after polymerization at $1637 \mathrm{~cm}^{-1}$ and $1608 \mathrm{~cm}^{-1}$ respectively, these two peaks were served as internal standards.

\section{7 In vitro cell attachment and proliferation of BMSCs}

Samples were prepared in glass tubes (cuboids with diameter of $4 \mathrm{~mm}$ and height of $2 \mathrm{~mm}$ ). rBMSCs (rat bone mesenchymal stem cells) were seeded in 96-well culture plates at a density of $2 \times 10^{4}$ cells/well. After one and five days of incubation, the attached rBMSCs were washed with PBS gently and fixed in $4 \%$ glutaraldehyd for $2 \mathrm{~h}$. Then, rBMSCs were dehydrated with an ascending concentration of ethyl alcohol $(30 \%, 50 \%$, $70 \%, 90 \%$, and $100 \%$ ) for 10 min each, dried in air for $8 \mathrm{~h}$, and sputtered with gold prior to observation.

The proliferation of rBMSCs was evaluated by Cell Counting kit-8 (CCK-8). Cells were seeded at a density of $5 \times 10^{3}$ cells/well in 96-well culture plates. After incubation periods of one, three, and five days in fresh DMEM(Dulbecco's modified Eagle medium), cells were cultured for another $4 \mathrm{~h}$ in CCK-8 solution at $37{ }^{\circ} \mathrm{C}$ in a humidified atmosphere of $5 \% \mathrm{CO}_{2}$. The level of proliferation of rBMSCs was determined by measurement of the optical density (absorbance at $450 \mathrm{~nm}$ ) by ELISA, and the cell growth curves were drawn.

\section{Results and discussion}

\section{1 Mechanical properties}

The results of mechanical properties including flexural 
strength, flexural modulus, elastic modulus, Vickers hardness, and fracture toughness are illustrated in Table 1.

Pure resin refers samples from monomer mixtures containing Bis-GMA and TEGDMA with a mass ratio of $50: 50$ that were cured at $70{ }^{\circ} \mathrm{C}$ for $16 \mathrm{~h}$. 550 and $850{ }^{\circ} \mathrm{C}$ refer the temperatures where the green bodies were sintered.

The flexural strength of cured pure resin is $181.08 \pm 12 \mathrm{MPa}$. However, the flexural modulus, Vickers hardness, and elastic modulus are so low that restrict its utilization in crowns, inlays, onlays, and veneers. When the sintered temperature is $850{ }^{\circ} \mathrm{C}$, the flexural strength attains a maximum of $181.13 \pm$ 8.12 MPa for samples cured at $70{ }^{\circ} \mathrm{C}$ for $16 \mathrm{~h}$. Flexural modulus, elastic modulus, and Vickers hardness show an increasing tendency with the increase of sintered temperatures of the green bodies. As high modulus and hardness are mainly properties of ceramics. The density of the $850{ }^{\circ} \mathrm{C}$ group is $73.7 \%, 5 \%$ higher than that of the $550{ }^{\circ} \mathrm{C}$ group. The increase of ceramic density contributes substantially to the higher flexural modulus, Vickers hardness, and elastic modulus of resultant composites. Fracture toughness is the result of inter-reaction between the resin networks and the partially sintered ceramic networks.

The results of brittleness indices calculated from Eq. (4) are also shown in Table 1. Brittleness index of the cured pure resin is $0.18 \pm 0.056 \mu \mathrm{m}^{-1 / 2}$, indicating the plasticity of cured resin. The values of composites vary from 0.75 to $1.32 \mu \mathrm{m}^{-1 / 2}$, which indicate an excellent machinability of the experimental restorative composites. As ceramics are essentially of brittleness, the machinability of composites decreases with densification of the green body.

Table 1 Density and mechanical properties of the experimental indirect restorative composites

\begin{tabular}{cccc}
\hline & Pure resin & $550{ }^{\circ} \mathrm{C}$ & $850{ }^{\circ} \mathrm{C}$ \\
\hline $\begin{array}{c}\text { Density (\%) } \\
\text { Flexural strength (SD) } \\
(\mathrm{MPa})\end{array}$ & $181.08(12)$ & $152.54(16.02)$ & $181.13(8.12)$ \\
$\begin{array}{c}\text { Flexural modulus (SD) } \\
(\mathrm{GPa})\end{array}$ & $3.67(0.24)$ & $15.27(0.69)$ & $20.06(0.16)$ \\
$\begin{array}{c}\text { Vickers hardness (SD) } \\
(\mathrm{GPa})\end{array}$ & $0.384(0.112)$ & $1.73(0.012)$ & $2.24(0.125)$ \\
$\begin{array}{c}\text { Elastic modulus (SD) } \\
(\mathrm{GPa})\end{array}$ & $5.31(0.93)$ & $20.44(2.92)$ & $26.65(0.87)$ \\
$\begin{array}{c}\text { Fracture toughness (SD) } \\
\left(\mathrm{MPa} \cdot \mathrm{m}^{1 / 2}\right)\end{array}$ & $2.09(0.22)$ & $2.29(0.21)$ & $1.70(0.10)$ \\
$\begin{array}{c}\text { Brittleness index (SD) } \\
\left(\mu \mathrm{mm}^{-1 / 2}\right)\end{array}$ & $0.18(0.056)$ & $0.75(0.01)$ & $1.32(0.08)$ \\
\hline
\end{tabular}

The fabricated polymer-infiltrated-ceramic-networks could mimic the natural dentin in mechanical properties. The comparison of mechanical properties among the experimental PICNs, the natural dentin and enamel, and two common commercial CAD/CAM blocks is shown in Table 2.

The flexural strength of the experimental composites $(152.54-181.13 \mathrm{MPa})$ is comparable to that of VITA ENAMIC and Lava Ultimate. The elastic modulus $(20.44-26.65 \mathrm{GPa})$ and fracture toughness $(1.70$ $\left.2.29 \mathrm{MPa} \cdot \mathrm{m}^{1 / 2}\right)$ resemble those of natural dentin $(8.7-$ $25 \mathrm{GPa}$ and $1.8-3.1 \mathrm{MPa} \cdot \mathrm{m}^{1 / 2}$ respectively). The elastic modulus of VITA ENAMIC is $30 \mathrm{GPa}$, higher than that of the natural dentin. This value of Lava Ultimate is $12.77 \pm 0.99 \mathrm{GPa}$, twice lower than that of the natural dentin. Both the higher and the lower elastic moduli could cause the mismatch between restorative materials and the residual parts of natural tooth, which would lead the early failure of restoration. Especially, the lower elastic modulus of Lava Ultimate would cause larger elastic deformation of the restorative materials and would ultimately cause debonding when used as crowns.

The Vickers hardness (1.73-2.24 GPa) is found to be between that of natural dentin $(0.51-0.92 \mathrm{GPa})$ and natural enamel (2.7-6.4 GPa), and more comparable to that of the natural dentin. Brittleness index is used to quantify the machinability of indirect dental restorative materials. The medium brittleness index value $(0.75-$ $1.32 \mu \mathrm{m}^{-1 / 2}$ ) indicates excellent machinability of the composites.

\section{2 Mid-infrared spectroscopy of cured/uncured pure resin}

The mid-infrared spectroscopy of cured pure resin is

Table 2 Comparison of the mechanical properties with commercial CAD/CAM blocks

\begin{tabular}{|c|c|c|c|c|c|}
\hline & $\begin{array}{c}\text { Flexural } \\
\text { strength } \\
(\mathrm{MPa})\end{array}$ & $\begin{array}{c}\text { Elastic } \\
\text { modulus } \\
(\mathrm{GPa})\end{array}$ & $\begin{array}{c}\text { Fracture } \\
\text { toughness } \\
\left(\mathrm{MPa} \cdot \mathrm{m}^{1 / 2}\right)\end{array}$ & $\begin{array}{c}\text { Vickers } \\
\text { hardness } \\
(\mathrm{GPa})\end{array}$ & $\begin{array}{c}\text { Brittleness } \\
\text { index } \\
\left(\mu \mathrm{m}^{-1 / 2}\right)\end{array}$ \\
\hline $\begin{array}{l}\text { Experimental } \\
\text { composites }\end{array}$ & $\begin{array}{c}152.54 \\
181.13\end{array}$ & $\begin{array}{c}20.44- \\
26.65\end{array}$ & $1.70-2.29$ & $1.73-2.24$ & $0.75-1.32$ \\
\hline Enamel & $\begin{array}{c}60-90 \\
{[5]}\end{array}$ & $\begin{array}{c}48-115 \\
{[2,10-12]}\end{array}$ & $\begin{array}{c}0.52-1.5 \\
{[2,12]}\end{array}$ & $\begin{array}{l}2.7-6.4 \\
{[10-13]}\end{array}$ & - \\
\hline Dentin & $\begin{array}{c}213-280 \\
{[5,14]}\end{array}$ & $\begin{array}{c}8.7-25 \\
{[12,15-18]}\end{array}$ & $\begin{array}{c}1.8-3.1 \\
{[2,16]}\end{array}$ & $\begin{array}{c}0.51-0.92 \\
{[18-20]}\end{array}$ & - \\
\hline VITA & & & & & \\
\hline $\begin{array}{c}\text { ENAMIC } \\
{[21]}\end{array}$ & $150-160$ & 30 & 1.5 & 2.5 & 1.67 \\
\hline $\begin{array}{c}\text { Lava } \\
\text { Ultimate }\end{array}$ & $\begin{array}{c}204 \pm 19 \\
{[22]}\end{array}$ & $\begin{array}{c}12.77 \pm 0.99 \\
{[22]}\end{array}$ & $\begin{array}{c}2.02 \pm 0.15 \\
{[22]}\end{array}$ & $\begin{array}{c}1.15 \pm 0.13 \\
{[20]}\end{array}$ & 0.57 \\
\hline
\end{tabular}


shown in Fig. 1, the results of which are used to calculate the degree of conversion. Because of the constancy of aliphatic $\left(1637 \mathrm{~cm}^{-1}\right)$ and aromatic $\left(1608 \mathrm{~cm}^{-1}\right)$ absorption in the mid-infrared spectroscopy before and after polymerization, the corresponding intensity could serve as internal standards to calculate the degree of conversion. The fraction of unconverted $\mathrm{C}=\mathrm{C}$ bonds is calculated by comparing intensity of $\mathrm{C}=\mathrm{C}$ and $\mathrm{C}-\mathrm{C}$ absorption. The calculated degree of double bond conversion is $82.17 \%$, which shows high degree of double bond conversion. This high degree of double bond conversion is assured through in vitro polymerization.

\section{3 Microstructures of the experimental PICNs}

The microstructures of the experimental PICNs are shown in Fig. 2. The green bodies were sintered at $550{ }^{\circ} \mathrm{C}$ (Fig. 2(a)) and $850{ }^{\circ} \mathrm{C}$ (Fig. 2(b)) respectively. The dark gray areas indicate polymer networks, while the light areas indicate ceramic networks. The partially sintered blocks were infiltrated with resin and cured at $70{ }^{\circ} \mathrm{C}$ for $16 \mathrm{~h}$. The SEM observation of the experimental composites indicates the inter-connecting of two phases, i.e., porous ceramics and polymers.

\section{4 Morphologies and proliferation of rBMSCs}

Biocompatibility is an indispensable factor to evaluate a given dental material. The fabricated PICN is one of indirect restorative composites which is fabricated by infiltrating polymerizable monomers into partially sintered porous lagoriolite blocks and cured. A study [7] shows that unpolymerized monomers exhibit oxygen-inhibition property. Cell culture represents a common method to evaluate biocompatibility of dental materials.

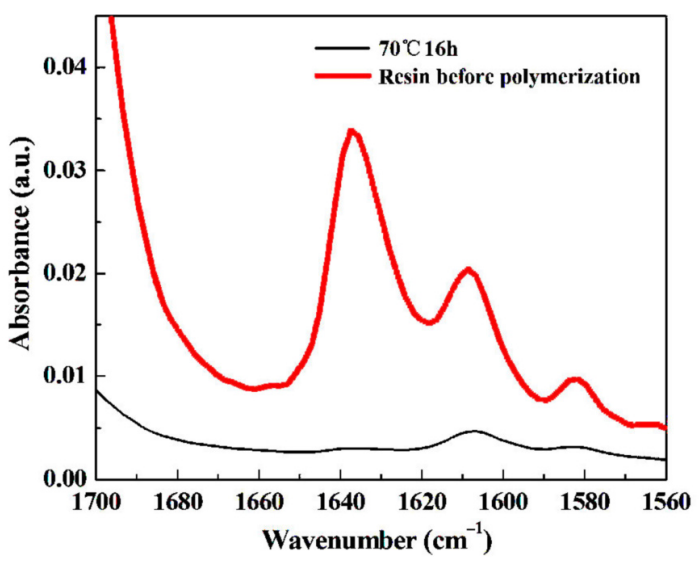

Fig. 1 Mid-infrared spectroscopy of cured pure resin.
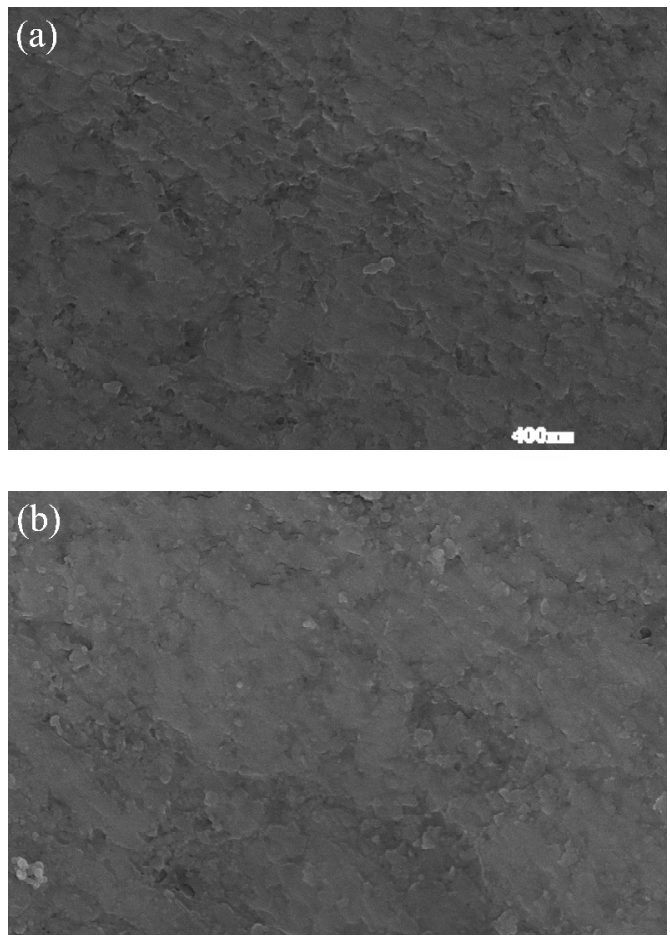

Fig. 2 SEM observation of the experimental PICNs: (a) secondary electron image of polished surface for green body sintered at $550{ }^{\circ} \mathrm{C}$, (b) secondary electron image of polished surface for green body sintered at $850{ }^{\circ} \mathrm{C}$.

Our results show that rBMSCs exhibit fibroblast-like spindle morphology (Fig. 3). Cells on the fifth day of culture grow more vigorously than those observed on the first day. There are more fusiform cells and larger cell spreading on samples on the fifth day of culture. Compared with those on the sample with PICN, the more long-spindle shaped cells are found on PICN than that on pure resin, which indicates that pure resin obviously stimulates the proliferation of rBMSCs in vitro.

Furthermore, the morphology of rBMSCs, to varying degrees, shows no apparent difference between the two groups (Figs. 3(c)-3(f)), indicating that the inter-reaction between the resin networks and the partially sintered ceramic networks have no effects the growth of rBMSCs (Fig. 4).

The proliferation of rBMSCs on samples was assessed with CCK-8 (Fig. 3). After five days of culture, there is no significant difference in the proliferation level of rBMSCs on the third day and the fifth day among all groups $(p>0.05)$. The number of cells kept increasing from day one to five among all groups. Cell number in all groups increased on day three and five which suggests that there is no contact inhibition of cells. 

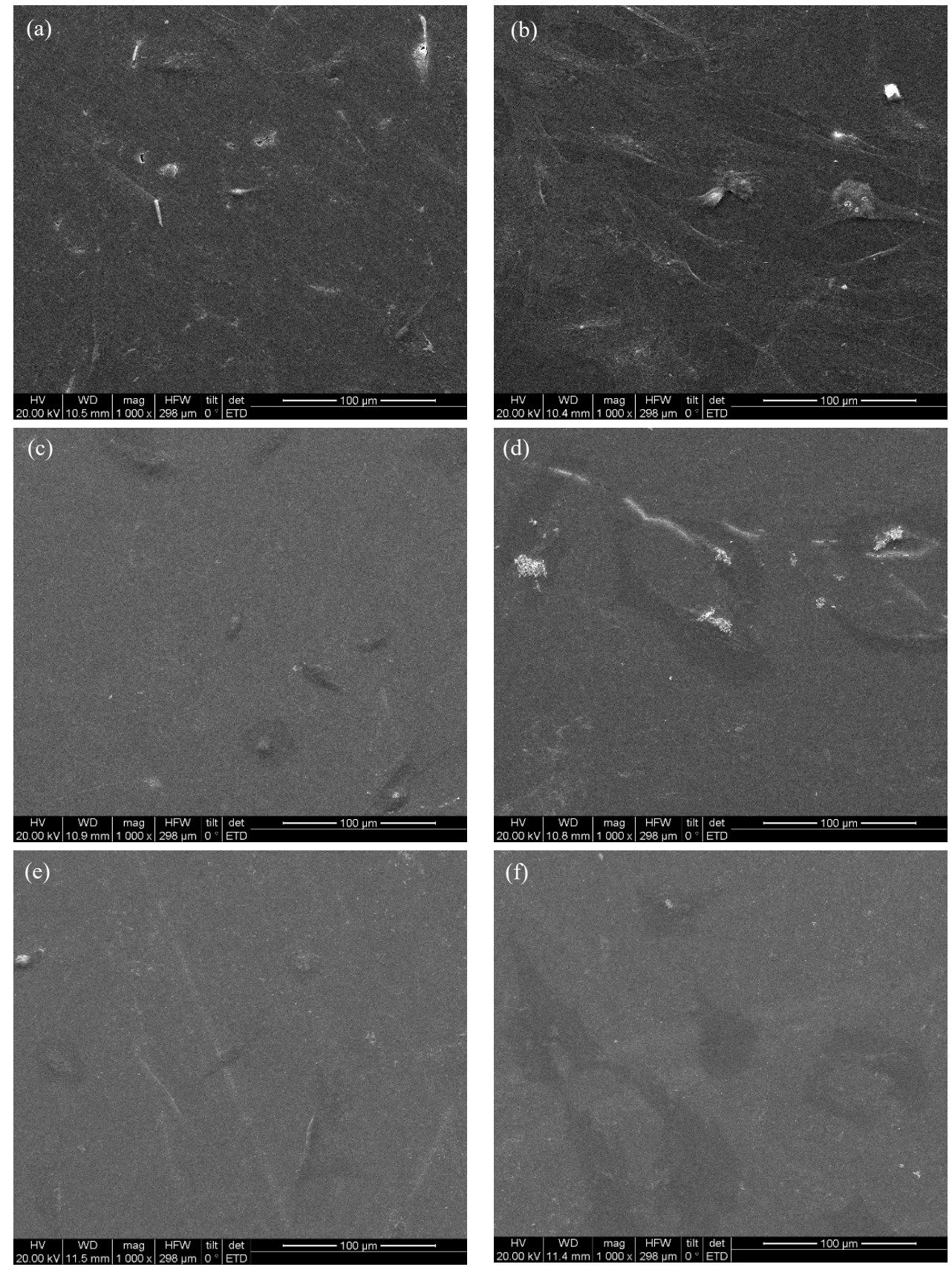

Fig. 3 Morphologies of rBMSCs after one- and five-day culture. (a, c, e) The morphologies of rBMSCs after one-day culture; (b, $\mathrm{d}, \mathrm{f}$ ) the morphologies of rBMSCs after five-day culture. (a, b) Pure resin; (c, d) $550{ }^{\circ} \mathrm{C}$-sintered PICN; (e, f) $850{ }^{\circ} \mathrm{C}$-sintered PICN.

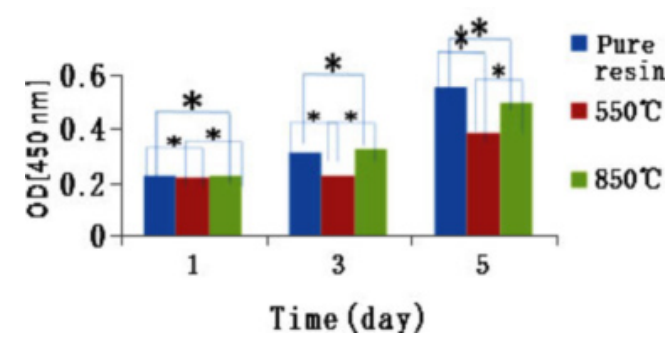

Fig. 4 Proliferation of rBMSCs determined by measurement of the optical density (absorbance at $450 \mathrm{~nm}$ ) in CCK-8 assay $\left({ }^{*} p>0.05\right)$.
The biocompatibility was evaluated through cell proliferation and CCK-8 in vitro. Our results show that proliferation of rBMSCs keeps similar increasing trend in samples. We conclude that the fabricated PICN shows good biocompatibility, indicating that the fabricated PICN is a potential material for further bioactive application.

\section{Conclusions}

An experimental PICN was fabricated through 
infiltrating methacrylate-based monomers into partially sintered ceramic blocks. The corresponding mechanical properties were investigated and evaluated in comparison with that of the natural tooth and two common CAD/CAM blocks. The mechanical results show that the increase in density of the green body brings about higher flexural strength, flexural modulus, elastic modulus, and Vickers hardness, but lower fracture toughness. The calculated brittleness index results indicate that higher density contributes to the brittleness of resultant composites. These composites reveal higher similarity to natural tooth in comparison with two common CAD/CAM blocks. Furthermore, the results of morphologies and proliferation of rBMSCs show the higher biocompatibility of these composites.

\section{Acknowledgements}

This work was financially supported by the National Natural Science Foundation of China (NSFC, Nos. 51532003, 51272181, 51672030, and 8127-1138).

\section{References}

[1] Cramer NB, Stansbury JW, Bowman CN. Recent advances and developments in composite dental restorative materials. $J$ Dent Res 2011, 90: 402-416.

[2] Coldea A, Swain MV, Thiel N. Mechanical properties of polymer-infiltrated-ceramic-network materials. Dent Mater 2013, 29: 419-426.

[3] Swain MV, Coldea A, Bilkhair A, et al. Interpenetrating network ceramic-resin composite dental restorative materials. Dent Mater 2016, 32: 34-42.

[4] Moszner N, Salz U. New developments of polymeric dental composites. Prog Polym Sci 2001, 26: 535-576.

[5] Sakaguchi RL, Powers JM. Craig's Restorative Dental Materials. Elsevier Health Sciences, 2012.

[6] Schmalz G, Arenholt-Bindslev D. Biocompatibility of Dental Materials. Heidelberg: Springer, 2009.

[7] Moharamzadeh K, Brook IM, Van Noort R. Biocompatibility of resin-based dental materials. Materials 2009, 2: 514-548.

[8] Schmalz G. The biocompatibility of non-amalgam dental filling materials. Eur J Oral Sci 1998, 106: 696-706.

[9] Chen MH. Update on dental nanocomposites. J Dent Res 2010, 89: 549-560.
[10] Cuy JL, Mann AB, Livi KJ, et al. Nanoindentation mapping of the mechanical properties of human molar tooth enamel. Arch Oral Biol 2002, 47: 281-291.

[11] Habelitz S, Marshall SJ, Marshall Jr. GW, et al. Mechanical properties of human dental enamel on the nanometre scale. Arch Oral Biol 2001, 46: 173-183.

[12] Xu HHK, Smith DT, Jahanmir S, et al. Indentation damage and mechanical properties of human enamel and dentin. $J$ Dent Res 1998, 77: 472-480.

[13] Craig RG, Peyton FA. The microhardness of enamel and dentin. J Dent Res 1958, 37: 661-668.

[14] Plotino G, Grande NM, Bedini R, et al. Flexural properties of endodontic posts and human root dentin. Dent Mater 2007, 23: 1129-1135.

[15] Ziskind D, Hasday M, Cohen SR, et al. Young's modulus of peritubular and intertubular human dentin by nano-indentation tests. J Struct Biol 2011, 174: 23-30.

[16] Kinney JH, Marshall SJ, Marshall GW. The mechanical properties of human dentin: A critical review and re-evaluation of the dental literature. Crit Rev Oral Biol M 2003, 14: 13-29.

[17] Meredith N, Sherriff M, Setchell DJ, et al. Measurement of the microhardness and Young's modulus of human enamel and dentine using an indentation technique. Arch Oral Biol 1996, 41: 539-545.

[18] Kinney JH, Balooch M, Marshall SJ, et al. Hardness and Young's modulus of human peritubular and intertubular dentine. Arch Oral Biol 1996, 41: 9-13.

[19] Lawn BR, Deng Y, Thompson VP. Use of contact testing in the characterization and design of all-ceramic crownlike layer structures: A review. J Prosthet Dent 2001, 86: 495-510.

[20] Albero A, Pascual A, Camps I, et al. Comparative characterization of a novel cad-cam polymer-infiltratedceramic-network. J Clin Exp Dent 2015, 7: e495-e500.

[21] VITA ENAMIC ${ }^{\circledR}$. Available at https://www.vitazahnfabrik.com/en/VITA-ENAMIC-24970,27568.html.

[22] Lava $^{\mathrm{TM}}$ Ultimate Restorative for CEREC $^{\circledR}$. Available at http://www.3m.com/3M/en_US/company-us/all-3m-produ cts/ /Lava-Ultimate-Restorative-for-CEREC-?N=5002385 $+8707795+8707799+8710706+8711017+8711723+87133$ $93+3294768924 \& \mathrm{rt}=$ rud.

Open Access The articles published in this journal are distributed under the terms of the Creative Commons Attribution 4.0 International License (http://creativecommons. org/licenses/by/4.0/), which permits unrestricted use, distribution, and reproduction in any medium, provided you give appropriate credit to the original author(s) and the source, provide a link to the Creative Commons license, and indicate if changes were made. 